\title{
The usefulness of an actor's perspective in lca
}

\author{
Henrikke Baumann ${ }^{2}$, Johanna Berlin ${ }^{3}$, Birgit Brunklaus ${ }^{2}$, \\ Mathias Lindkvist ${ }^{2}$, Birger Löfgren ${ }^{1,2}{ }_{*}$ and Anne-Marie Tillman ${ }^{2}$ \\ ${ }^{1}$ SKF Sverige AB, Göteborg, Sweden \\ ${ }^{2}$ Chalmers University of Technology, Department of Energy and Environment, Göteborg, \\ Sweden \\ ${ }^{2}$ SIK - the Swedish Institute for Food and Biotechnology, Göteborg, Sweden \\ *birger.lofgren@skf.com
}

\begin{abstract}
This paper is an argumentation for adding an actor's perspective to lifecycle assessment (LCA). The need for this perspective stem from a criticism about the usefulness of LCA interpretation methods comparing the relative contribution of life-cycle phases of a product. Our argumentation is based on four previously published studies providing practical examples of how value chain actors' influence may be considered in an LCA and the benefit of doing so. Manufacturing sector examples show how one company's influence can be illustrated in results and how it may relate all relevant emissions to its own processes. The food sector study shows how to assess several value chain actors' individual improvement potential. The final example, taken from building sector, explore how to consider the fact that actors in one part of the value chain can influence other actors to improve.
\end{abstract}

\section{Problem and solution}

Life-cycle assessment (LCA) is a tool that illustrates the entire life cycle of products and services and quantify their environmental impacts. A frequently asked question in LCAs is "which part of the life cycle contribute the most to the environmental burden of a product/ service?" and the most common method used is the dominance analysis. A dominant use phase contribution to global warming is found in most products consuming energy during product application like cars, computers, and light bulbs. In the case of animal food products, such as milk and yogurt, the agricultural processes usually dominate the life-cycle environmental impact. These are typical examples of how one can learn and pinpoint so called hotspots in the product life cycle when using LCA. 
However, to what extent does such analysis underpin an improvement of the situation? Is the conclusion of the analysis relevant for the receiver of the results, or, in other words, to what extent can he or she influence? It is our experience that LCA's holistic nature often urges the analyst to define very broad goals, forgetting that no decision maker alone can influence the whole value chain of a product. Policy maker's power of influence is limited by national borders and industrial actors and consumers are limited by their location in the value chain. Results based on an analysis not taking this into account risk to mislead actors into underestimating their ability to influence and improve the product, especially if they are not acting in the dominating phase of the product life cycle. Should a worker in manufacturing stop bothering about the environmental consequences of the product he is producing if the results from an LCA contribution analysis show that the contribution of his processes is only a small fraction of the total?

The fundamental difference between an LCA with an actor's perspective and contributional analysis, as we know it, is that the sphere of influence of actors, such as organizations, companies, institutions or even specific work roles within these, are considered in the former. Contribution analysis typically compare lifecycle phases or technically defined processes.

The importance of an actor's perspective has been highlighted since the beginning of LCA and the broader field of Industrial Ecology, see e.g. [1-3]. However, developments in theory and practice including an actor's perspective are rarely found. Baumann [4] has proposed a whole new research area for understanding how organizations influence the environment. In this paper we highlight the usefulness and value of adding an actor's perspective to the LCA methodology by discussing four previously published studies where this perspective is applied. They have in common a criticism of dominance analysis in LCA but the alternative approaches varies and highlights different aspects. In the LCA textbook by Baumann \& Tillman [5] an early example is given where one company's influence is illustrated in flowcharts and bar charts. Further work specifically considering the perspective of one actor in the value chain is presented in the manufacturing sector study by Löfgren [6]. He formulated a formal method to consider only the parts that are relevant for people working in manufacturing at a specific company in the value chain. The food sector study [7] introduced a way to from the perspective of several value chain actors assess their individual improvement potential. The final example is taken from building sector where Brunklaus et al. [8] explore how to consider the fact that actors in one part of the value chain can influence other actors to improve. 


\section{First example: decision maker analysis}

An early example where an actors perspective is applied in LCA is a "decision maker analysis" found in textbook on LCA [5]. The analysis was made for the manufacturing company SKF and was based on data from a study by Ekdahl [9]. The basis for this type of analysis is the identification of the different companies and organizations that carry out the different activities in the technical system. This can be used to identify the extend to which environmental impact is under a certain company's control. The flow chart, in Fig 1, shows the relationship between commissioner and other companies and five levels of influence where identified.

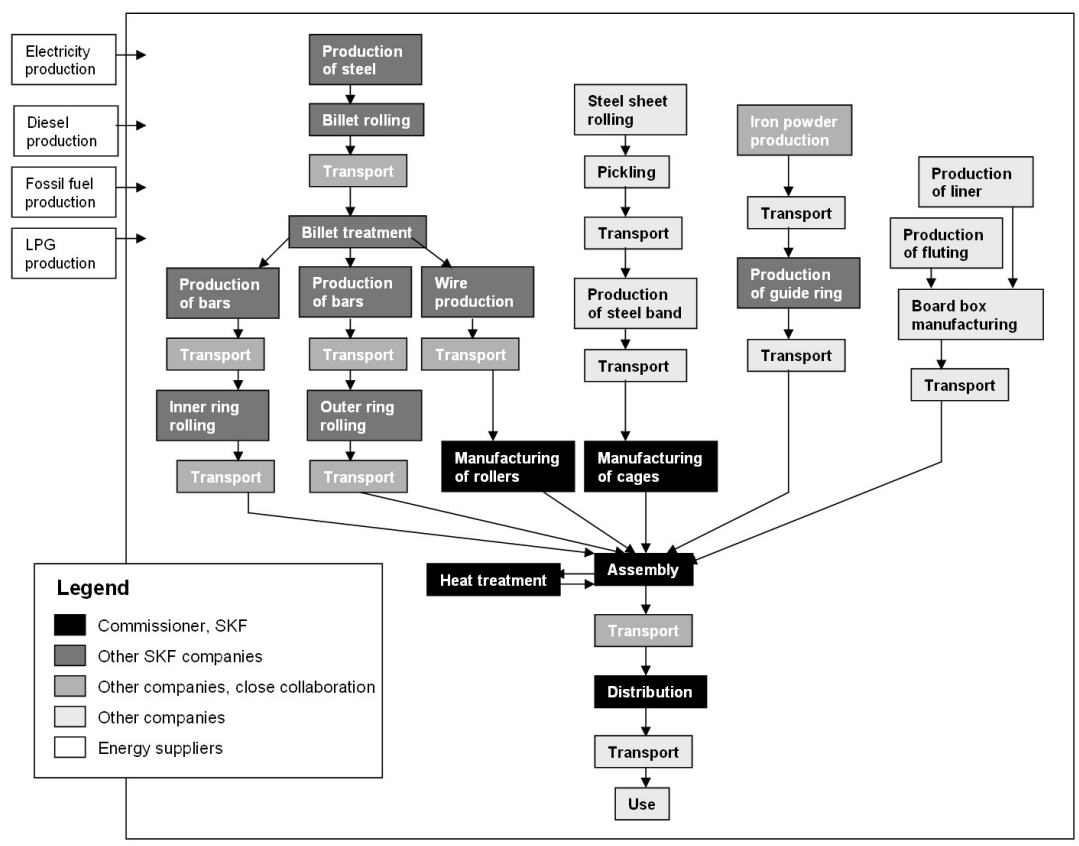

Fig.1: Flow chart for the decision maker analysis of an SKF roller bearing. [5]

Based on the information results can be presented as in Fig 2, where environmental impacts are related to the different actors. To reduce emissions to air (e.g. $\mathrm{CO} 2, \mathrm{SO} 2, \mathrm{NOx}$ and $\mathrm{CH} 4$ ) the decision maker needs to influence the choice of energy suppliers. 


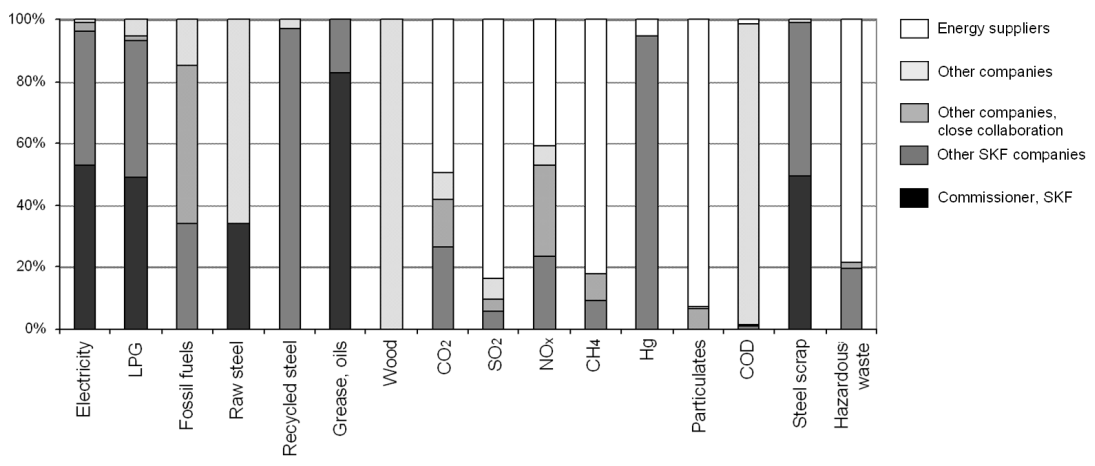

Fig.2: Environmental impacts related to different actors. [5]

\section{Example 2: Relating life-cycle consequences manufacturing actors}

In a more recent study at SKF [6], the company wanted to better understand the environmental consequences from manufacturing a bearing unit. The company was specifically interested in how results could be presented to make better sense to SKF employees working in manufacturing, namely to inform them of how they, in their daily work, could increase the environmental performance of manufacturing processes.

The initial dominance analysis showing the $\mathrm{CO}_{2}$-eq. emissions, during the manufacturing of the bearing unit, distributed on SKF manufacturing processes, tier 1 supplers, steel production and other suppliers, indicated that steel production was the hotspot. SKF processes' contribution was only a smaller part of the emissions.

When these results were presented to manufacturing actors in the company they were perceived as less relevant, since they did not give an immediate picture of how they could increase the environmental performance of their processes. So, to increase the relevance, the results were first reformulated by relating all upstream emissions to in-house activities, see left side of Fig. 3.

The next step was to ensure that the results presented related to the work of the company's manufacturing actors; i.e. to ensure that the results only contained environmental consequences that could be improved by their actions in manufacturing. Considering that the $\mathrm{CO}_{2}$-eq. emissions related to the production 
of component material remaining in the product when it is shipped to customer, is primarily dependent on the design of the product - and not on how it was manufactured at SKF - this part was omitted from the results, given to the right of Fig. 3.

This bar chart now illustrated a radically different picture of the environmental consequences for SKF manufacturing actors from that given by the more conventional dominance analysis. General improvement strategies for SKF manufacturing processes were clearly revealed from the bar chart as (1) designing production processes that reduces the material removed by machining, (2) increasing electricity use efficiency, and (3) decreasing scrap rate.

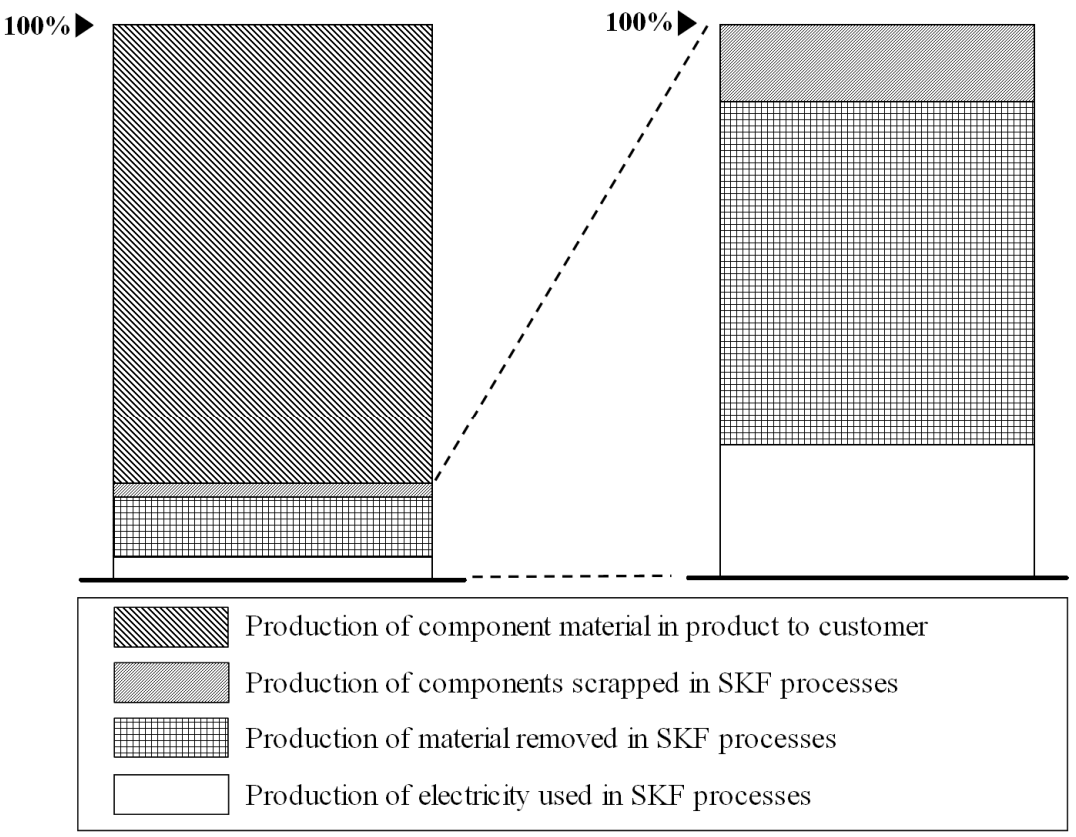

Fig.3: To left: Distribution of $\mathrm{CO}_{2}$-eq. emissions for production of one bearing unit (reformulated dominance analysis) - To right: Distribution of $\mathrm{CO}_{2}$-eq. emissions for manufacturing of one bearing unit at SKF (dominance analysis from the perspective of manufacturing actors at SKF). [6]

Fig.4 shows how Löfgren [6] generalized the method to draw system boundaries in LCA based on a company's manufacturing actors' perspective. In this figure we see how the method disregards part of the production of direct material, and only 
includes the fraction equivalent to the component material losses from the actor's manufacturing system.

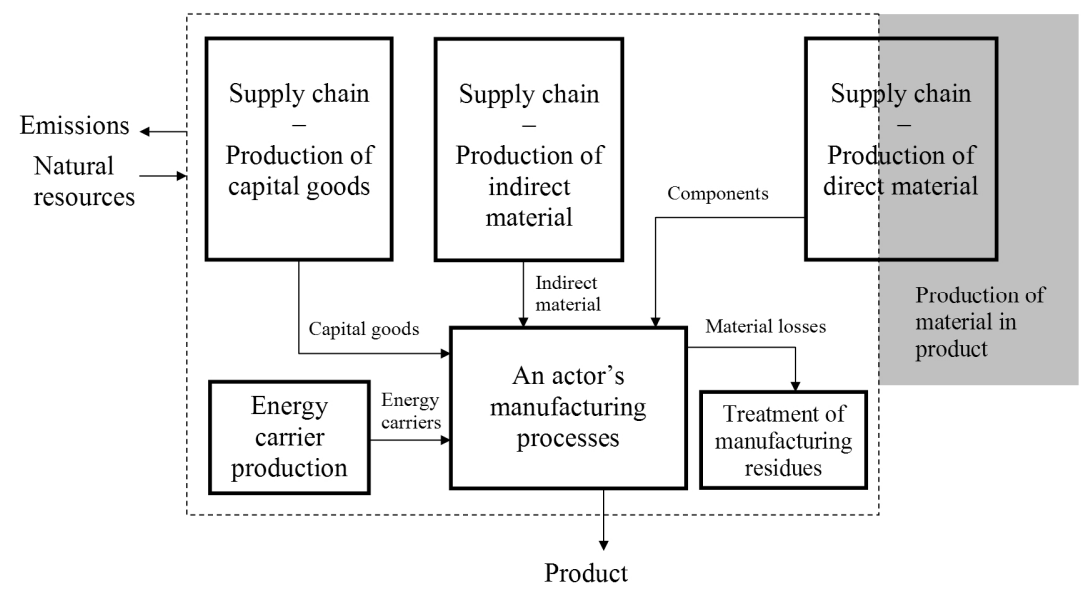

Fig.4: System boundaries when relating environmental consequences to an actor's manufacturing processes. Supply chain production of capital goods, direct and indirect material, and energy carriers includes all upstream processes required for production. The part corresponding to material in product is partitioned away from the processes for producing direct material. [6]

\section{Example 3: Assessing actions by milk chain actors}

The challenge in working with environmental improvements is to select the action offering most substantial progress. As we could see in the previous examples, not all actions are open to all actors in a product chain. This study by Berlin et al. [7] demonstrates how LCA may be used to explore the environmental consequences from the actions of several actors the Swedish post-farm milk chain.

The potential improvement actions were first identified in a brainstorming session with the researchers involved in this project, which utilized their understanding of life cycle thinking and LCA methodology, combined with their experience in LCA studies of dairy products.

First, the post-farm milk chain was divided into the main actors; the dairy industry, the retailers and the consumers. Their potential actions to green the milk chain were then listed. Although the same actions were not identified for all 
actors, they could be sorted under the main strategies of improved energy efficiency, changed transport patterns, reduction of product losses, and use of ecological labeling. The same strategies were highlighted as areas with environmental improvement potential through an analysis of the trends in the dairy sector. It needs to be pointed out that although most of these strategies are relevant for all actors, they would not imply the same action for the different actors. The potential for the actors to improve in any of the four aspects; namely energy efficiency, transportation, product losses, and use of ecological labeling, was then quantified through literature studies and estimations.

The quantified results from the study were presented as the total life cycle environmental impact for milk, cheese and yoghurt separately in the study. The results in Fig.4 are an example of how the result looked like for the actor household and type of undertaken improvement measures for the environmental impact categories of Global Warming Potential. Energy use, Eutrophication as well as POCP.

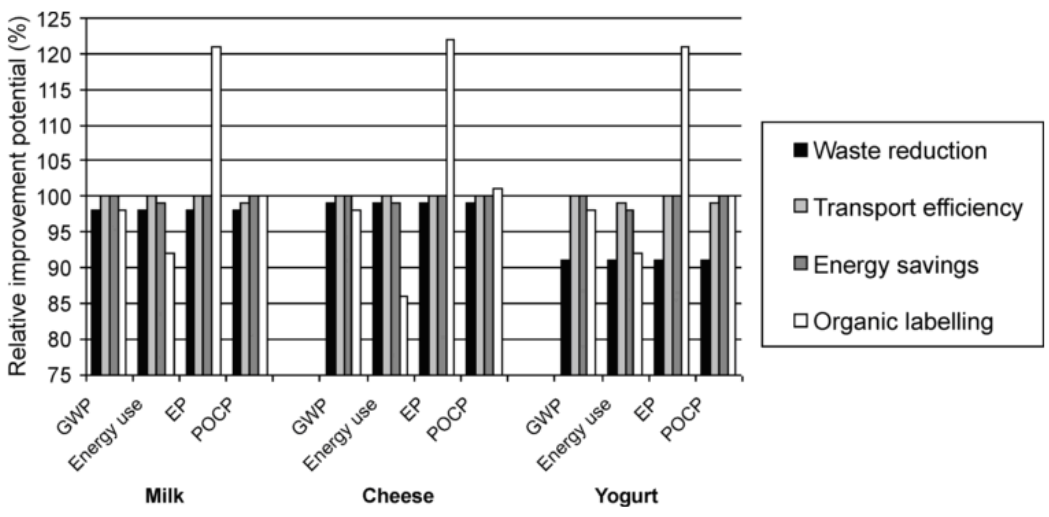

Fig.4: The household's environmental improvement potential to reduce waste, increase transport efficiency, save energy, and buy organic products, in relation to today's environmental life cycle contributions of milk, cheese, and yogurt. 100 represents the present situation; bars lower than 100 mean improvement, and those above 100 mean impairment. GWP = global warming potential; $\mathbf{E P}=$ eutrophication; $\mathbf{P O C P}=$ photochemical ozone creation potentials. [7]

The most efficient improvement actions for the dairies, retailers and households are listed below: 
- Dairy: No improvement action is clearly superior to the other, but reducing waste appears to contribute to a lower environmental impact for most impact categories for all three products.

- Retailer: Decreased use of energy for cold storage and display seem to be the most efficient improvement action.

- Household (fig.4): Reducing waste is the improvement action that gives clearly positive results for all effect categories included. By choosing organic products, the improvements in energy use for milk and cheese appear to be even greater, but the eutrophication rises. Overall, the household has the largest improvement potential, and yoghurt is the product that offers the greatest improvement.

Two aspects of methodology were highlighted by this study. One is the necessity of the systemic approach, the life cycle perspective, to describe the full effect of a potential improvement, in particular reducing waste. To lower waste decreases all inputs and emissions needed upstream in the system; hence waste avoided later in the chain is more important than that avoided earlier in the life cycle. The second is the usefulness and feasibility of the actor analysis.

\section{Example 4: Building chain actors' relative importance}

In our final example Brunklaus et al. [8] present an approach for considering the choices of value actors in LCA, similar to our previous example by Berlin et al. [7]. However, in this study LCA results are understood as the sum of choices in order to assess the total potential of greening buildings and the actors' relative importance, rather than bringing forward the most effective actions for each individual actor. This study also introduces the perspective that actors can influence each other by putting demands on each other.

The studied LCA systems (i.e. one conventional housing and two variants of passive housing) were assessed in terms of the value chain actors' green options for electricity supply, transportation and heating. The results were analyzed with regard to respective actor's environmental significance for the life cycles of the studies housing cases. By comparing results for conventional and green choices in Fig. 5 we see that residents appear to be the most influential environment actor - a conclusion that is different from the common view within the sector, namely that the building constructors are environmentally most important. A summary of conclusions from the 'green choices' scenarios are given below: 
- Residents have the most environmental influence by choosing ecolabelled electricity.

- Construction companies have the least influence with their green transport choices. However, construction companies can recommend that residents choose eco-labelled electricity.

- The material producer's importance becomes even greater when residents and construction companies start making greener energy choices.

The introduction of passive house technology shifts responsibilities from district heating producers to residents, due to the technology's reduced heating requirements. This shift of environmentally most significant actor is presently not communicated, and occupants of passive houses may not be aware of the great significance of their choice of electricity supplier has for the overall environmental consequences.

The strength of the methodology applied here is that more emphasis is placed on the interpretation of results and it is therefore more usable for actors. The methodology focuses on identifying the environmentally important actors and actions instead of technology and production phases. Recommendations may also be useful to foster collaboration. 

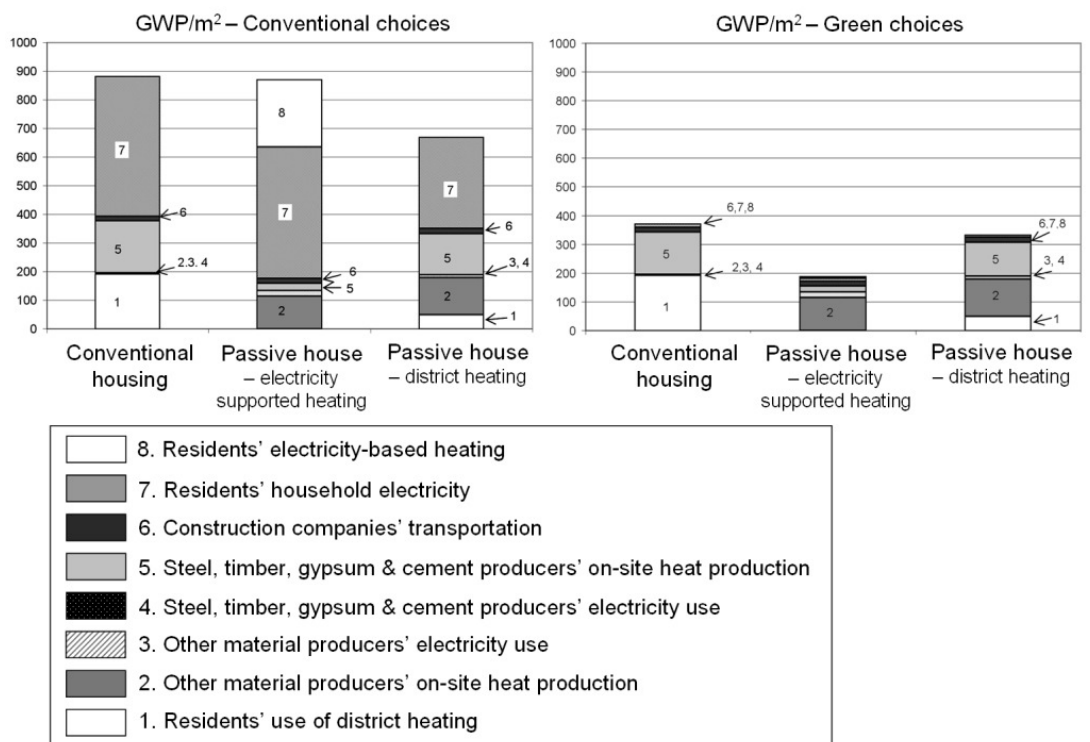

Fig.5: Environmental impacts of actors in the buildings chain depending on their choice. All actors with either conventional choice (left) or green choice (right). GWP = $\mathrm{kgCO}_{2}$-eq. Modified from [8].

\section{Conclusions and outlook}

Löfgren [6] points out that the concept life-cycle thinking includes underlying assumptions about a broadened responsibility for actors in the product chain [10]. In the LCA interpretation methods described here, this new responsibility structure becomes more apparent by assessing actors influence on environmental impact. If a company, for example, declares all direct and indirect emissions related to its processes, in accordance to an industrial standard for greenhouse gas accounting and reporting [11], that company also acknowledges that all these emissions are consequences of its own activities. This mindset represents more than merely systems thinking, since it considers not only the cradle-to-grave implications for the environment, but also implies that the company assumes moral responsibility for them.

LCA studies often do not take this into account, when they are interpreted with dominance analyses to see what life cycle phases and particular environmental loads contribute the most to the overall results. In LCA there are seldom 
interpretations of the sphere of influence of the various actors along the product chain, giving a concrete example of the need for the inclusion of actors in environmental assessment, as noted by e.g. Berkel et al. [1], Andrews [2], Heiskanen [3] and Baumann [4]. The four examples in this paper has demonstrated the feasibility of such an approach, showing that the life cycle environmental implications of improvement potentials can be quantified on an actor basis and, more important, the usefulness of doing so.

The methodological contributions in the examples provide us with options for modeling LCAs to

- identify to which extend the environmental impact is under an actor's control [5],

- understand how energy and material flows in a specific actor's processes relates to environmental consequences no matter where in the value chain they might occur [6],

- focus on the environmental consequences that a manufacturing actors in a certain company is able to influence [6],

- divide LCA results by value chain actors rather than life-cycle phases/processes, and assessing best improvement action for each actor [7],

- evaluating most influential actor [8], and

- evaluate the impact from actors ability to put demand on other actors in the value chain [8].

From our experience, it is clear that these approaches to interpret and present LCA results add value to receivers of results. It is therefore important to continue learning about how this may be done and the practical implications of it. We see an increasing interest in understanding how the practice of people in organizations influence the technical systems, of which one example is the area of organizing for the environment [12].

\section{References}

[1] Berkel, René, Esther Willems, and Marije Lafleur. The Relationship between Cleaner Production and Industrial Ecology. Journal of Industrial Ecology. Vol 1, No. 1, 1997, 51-66.

[2] Andrews, C J. Building a micro foundation for industrial ecology. Journal of Industrial Ecology. Vol. 4, No. 3, 2000, 35-51. 
[3] Heiskanen, Eva. Institutionalization of Life-Cycle Thinking in the Everyday Discourse of Market Actors. Journal of Industrial Ecology. Vol. 4, No. 4, 2000, 31-45.

[4] Baumann, Henrikke. Environmental assessment of organising: towards a framework for the study of organisational influence on environmental performance. Progress in Industrial Ecology, Vol. 1, No. 1/2/3, 2004, 292306.

[5] Baumann, Henrikke, and Anne-Marie Tillman. The hitchhiker's guide to $L C A$ : an orientation in life cycle assessment methodology and application. Lund: Studentlitteratur, 2004.

[6] Löfgren, Birger. Capturing the life cycle environmental performance of a company's manufacturing system. Licentiate thesis. Chalmers University of Technology. 2009.

[7] Berlin, Johanna, Ulf Sonesson, and Anne-Marie Tillman. Product Chain Actors' Potential for Greening the Product Life Cycle. Journal of Industrial Ecology Vol. 12, No. 1, 2008, 95-110.

[8] Brunklaus, Birgit, Catarina Thormark, and Henrikke Baumann. 2010. Illustrating limitations of energy studies of buildings with LCA and actor analysis. Building Research \& Information Vol. 38, No. 3, 2010, 265-279.

[9] Ekdahl, Å. Life Cycle Assessment on SKF' s Spherical Roller Bearing. MSc Thesis. Chalmers University of Technology. 2001.

[10] Heiskanen, E. The institutional logic of life cycle thinking. Journal of Cleaner Production. Vol. 10, No. 5, 2002, 427-437.

[11] Ranganathan, Janet; Laurent; Corbier, Pankaj; Bhatia, Simon; Schmitz, Peter; Gage, and Kjell Oren. The Greenhouse Gas Protocol: A Corporate Accounting and Reporting Standard - revised edition. World Resources Institute. 2004.

[12] <http://www.gronorg.se/index-filer/index_en.htm>, (Accessed 14.04.2011). 